\title{
Implementing High-Quality Primary Care Through a Health Equity Lens
}

\author{
Azza Eissa, MD, $P b D^{1,2,3}$ \\ Robyn Rowe, $P b D^{4,5}$ \\ Andrew Pinto, MD, MSc $c^{1,2,3}$ \\ George N. Okoli, MD, MSc ${ }^{6}$ \\ Kendall M. Campbell, $M D^{7}$ \\ Judy C. Wasbington, $M D^{8}$ \\ José E. Rodríguez, $M D^{9,10}$
}

Institute of Health Policy, Management and Evaluation, Dalla Lana School of Public Health, University of Toronto, Toronto,

Ontario, Canada

${ }^{2}$ Department of Family and Community Medicine, Faculty of Medicine, University of Toronto Toronto, Ontario, Canada

${ }^{3}$ Upstream Lab, MAP/Centre for Urban Health Solutions, Li Ka Shing Knowledge Institute, Unity Health, Toronto, Ontario, Canada

${ }^{4}$ ICES Central, Strategic Partnerships \& Digital Services, Indigenous Data Team, Kingston, Ontario, Canada

${ }^{5}$ Health Data Research Network Canada, Indigenous Data Team, Vancouver, British Columbia, Canada

${ }^{6}$ George and Fay Yee Centre for Healthcare Innovation, Max Rady College of Medicine, Rady Faculty of Health Sciences, University of Manitoba, Winnipeg, Manitoba, Canada

${ }^{7}$ Department of Family Medicine, University of Texas Medical Branch, Galveston, Texas

${ }^{8}$ Atlantic Medical Group, Overlook Family Medicine Residency Program, Summit, New Jersey

${ }^{9}$ Department of Family and Preventive Medicine, University of Utah Health, Salt Lake City, Utah

${ }^{10}$ Office of Health Equity, Diversity \& Inclusion, University of Utah Health, Salt Lake City, Utah

Conflicts of interest: authors report none.

\section{CORRESPONDING AUTHOR}

José E. Rodríguez

University of Utah Health

26 South 2000 East

5750B EHSEB

Salt Lake City, UT 84112

lose.rodriguez@hsc.utah.edu

\begin{abstract}
The COVID-19 pandemic highlighted the importance of centering health equity in future health system and primary care reforms. Strengthening primary care will be needed to correct the longstanding history of mistreatment of First Nations/Indigenous and racialized people, exclusion of health care workers of color, and health care access and outcome inequities further magnified by the COVID-19 pandemic. The National Academies of Sciences, Engineering, and Medicine (NASEM) released a report on Implementing High-Quality Primary Care: Rebuilding the Foundation of Health Care, that provided a framework for defining high-quality primary care and proposed 5 recommendations for implementing that definition. Using the report's framework, we identified health equity challenges and opportunities with examples from primary care systems in the United States and Canada. We are poised to reinvigorate primary care because the recent pandemic and the attention to continued racialized police violence sparked renewed conversations and collaborations around equity, diversity, inclusion, and health equity that have been long overdue. The time to transition those conversations to actionable items to improve the health of patients, families, and communities is now.
\end{abstract}

Ann Fam Med 2022;20:Online. https://doi.org/10.1370/afm.2785.

Annals "Online First" article. Accepted for publication in a later issue.

\section{INTRODUCTION}

he COVID-19 pandemic affected health care service worldwide, ${ }^{1}$ and exacerbated and exposed systemic racial and ethnic health care inequities. Ideally, as we begin to forge a path forward, health care reform efforts will focus on providing equitable access to high-quality health care. Primary care, with its focus on the health of both individuals and communities, could play a key role in addressing health inequities. ${ }^{2-6}$ Chronic underinvestment in primary care, particularly in the United States, however, currently limits its impact on health disparities.

Policy makers in the United States and Canada have recognized the need for primary care reform and for adopting strategies that lead to more equitable and accessible high-quality care for their populations. ${ }^{7}$ Recently, the United States and Canada ranked last and next to last, respectively, in health equity, health care outcomes, and overall performance ranking among 11 high-income countries. ${ }^{8}$ The top-performing countries overall were Norway, the Netherlands, and Australia. ${ }^{8}$ Most developed countries spend an estimated $12 \%$ to $17 \%$ of total health expenditure on primary care, whereas the United States spends an estimated $5.4 \% .{ }^{9}$ Countries that invest in primary care have better population health, lower health costs, better health care utilization patterns, and reduced mortality. ${ }^{10}$

The disproportionate toll on Black, Latinx, and Indigenous communities in the United States from the COVID-19 pandemic has amplified the need for a more culturally and linguistically diverse primary care workforce. ${ }^{11}$ In Canada, while the workforce of physicians has been steadily growing, it has not kept up with its population growth, increased immigration, and cultural diversity. ${ }^{12}$ As a result, historically and structurally marginalized groups such as First Nations people living in remote rural communities continue to experience inadequate access to health care and poor health outcomes. ${ }^{13,14}$ Patients in both the United States and Canada face primary care access inequities and, consequentially, risk a higher burden of illness and resulting comorbidities. ${ }^{15,16}$ Despite divergence between the United States and Canadian health care system infrastructure, there is much to learn from one another in the pursuit of equitable health reform and recovery. 
The recommendations released in the National Academies of Sciences, Engineering, and Medicine (NASEM) report, Implementing High-Quality Primary Care: Rebuilding the Foundation of Health Care, ${ }^{7}$ have generated much discussion. ${ }^{17,18}$ The report recommends the US Department of Health and Human Services (HHS) establish a Secretary's Council on Primary Care and make it the accountable entity for primary care and an Office of Primary Care Research at the National Institutes of Health (NIH). This 2021 report is built upon the foundational work that defined primary care 25 years ago, the Institute of Medicine report Primary Care: America's Health in a New Era. ${ }^{19}$ The 1996 US-based report recommended implementing a primary care system that would provide universal insurance coverage and enable adequate health care career training opportunities. This model is comparable to Canada's publicly funded health care system. It is important to note that, as in the United States, the Canadian health system was built upon systemically rooted structures of discrimination, racism, and inequities. ${ }^{20}$ Leveraging health care systems knowledge from both Canada and the United States this special article aims to apply a health equity lens to the 5 recommendations put forward in the 2021 NASEM report. We hope to advance global initiatives and discussions aimed at meaningful and equitable health reform by placing highquality primary care at the center.

\section{Recommendation 1: Pay for Primary Care Teams to Care for People, Not for Doctors to Deliver Services} While teams have been important in health care for decades, payment structures in the United States have largely relied on billing for physician-delivered services. ${ }^{18}$ The idea of rewarding the team instead of the doctor leads to a broader rethinking of how we reimburse for medical care. The NASEM report defines teams broadly, including physicians, dentists, pharmacists, nurse practitioners, physician assistants, medical assistants, community health workers, etc. Among these professions, those employed in the lowestpaying jobs (ie, medical assistants, community health workers) are often minoritized individuals from various ethnic and racialized backgrounds. ${ }^{21-24}$ As teams become more race concordant with individual patients, health care outcomes will likely improve..$^{25,26}$

Ideally, team leaders will be from diverse backgrounds in order to establish a more equitable vision for health care organizations and to increase the probability that the needs of underserved communities are met. Changes in admissions processes for medical, nursing, dental, pharmacy, and other health professional schools are necessary to ensure that team leadership is equitable, because Black, Latinx, American Indian/Alaska Native/First Nations, and Pacific Islanders remain underrepresented in those professions. ${ }^{27-30}$ In addition, holistic admissions honoring distance traveled and individual experiences should be equitably implemented throughout professional training programs in health care. ${ }^{31}$ As we diversify health care teams to care for people, it is important to ensure that team members from under-represented backgrounds are not burdened with "minority taxes" (ie, the sum of inequitable distribution of extra responsibilities and uncompensated work in the name of diversity), which hinder participation in medical education and research initiatives. ${ }^{32-35}$ Minority taxes also contribute to the lack of diversity in leadership, and research teams needed to codesign equitable solutions. ${ }^{36}$ In transitioning to paying teams to care for people, input from diverse, underserved communities can highlight inequities and redefine high quality health care, ${ }^{36}$ guiding decision makers toward more equitable solutions.

Some nations have adopted primary care financing reforms including capitation and team-based care, although these can result in inequitable resource allocation of health services (eg, declining to enroll people with mental health disorders). ${ }^{37}$ To avoid having inequitable allocation of health services as an unwanted effect of payment reform, health systems should consider "need-based formulas" in their reimbursement models. ${ }^{38}$ Implementing high-quality care will also require facilitating multi-payer collaborations and increasing the overall portion of health care spending on primary care.

\section{Recommendation 2: Ensure That High-Quality Primary Care is Available to Every Individual and Family in Every Community}

All individuals should have access to a primary care clinician in a strong health care system. While there are no quick fixes to ensuring primary care access for everyone, several initiatives have been shown to improve access. For example, access to timely care can mediate important health outcomes. In Canada, Ontario's experience suggests that incentivizing primary care teams to improve after-hours clinic access outside regular working hours helps to reduce emergency department visits. ${ }^{39}$ As we develop policy initiatives targeting increased primary care access, we need to maintain the spotlight on issues of equity.

An intersectoral health systems approach can deliver equitable and sustained access to high-quality primary care. Interventions that focus on community engagement, outreach programs (fixed or mobile), housing, case management, and integration of services are essential to ensuring that traditionally underserved populations (ie, homeless, incarcerated, and those with mental illness and substance use disorders) have access to high-quality primary care ${ }^{40-43}$ For example, access to psychiatric care and expansion of mental health services was improved in Indigenous Cree communities in Manitoba, Canada, by using an intersectoral community-based approach that connected mental health services to primary care for adults. ${ }^{43}$ Overall, investments in sustained longitudinal teambased care and creation of health centers in areas with primary care shortages need to be prioritized.

Identifying individuals who do not currently have a connection to a primary care clinician, possibly by using electronic medical records (EMR), could drive outreach to help such individuals connect with primary care teams in their 
communities. To ensure an adequate supply of primary care teams in underserved communities, health care systems can use geocoded information highlighting underserved neighborhoods to guide expansion decisions. Improving Medicaid reimbursement levels would incentivize service delivery in underserved areas. Incentives for recent graduates to work in rural and underserved settings should be expanded.

\section{Recommendation 3: Train Primary Care Teams Where People Live and Work}

The health care needs of increasingly diverse populations in the United States and Canada are greatly challenged by population density and geography. For example, in rural United States, the primary care physician per patient ratio is about 39.8 per 100,000 compared with 53.3 per 100,000 in US urban areas, ${ }^{44}$ even though chronic diseases such as diabetes and coronary artery disease are more prevalent in rural areas. ${ }^{45}$ Similarly, only 22 dentists are available per 100,000 patients in rural United States compared with 30 per 100,000 in US urban areas. ${ }^{46}$ Health care professionals and patients in rural and remote areas face vastly different obstacles from those in urban areas, including cultural and social differences, educational gaps, economic deprivation, and geographic isolation, all of which contribute to the immense health care inequities experienced in rural areas. For instance, Indigenous people and communities in remote areas of Canada face unique health access challenges with fewer health care services, and in many instances, access is fly-in only. As a result, hiring and retention in these communities is difficult, and the time needed to build trusting relationships with primary care clinicians is hampered. In addition, people living in indigenous reserves and rural regions tend to have higher rates of illnesses and increased prevalence of comorbidity and multimorbidity. Health care professionals trained to work and live in the communities they serve would develop a deeper understanding of the community's cultural and health needs and train to provide holistic care as primary care clinicians.

Potential health care team members who live in rural and some underserved urban areas may not have access to training opportunities. The US Department of Education and the US Department of Health and Human Services should partner to expand educational pathways to increase opportunities for students from rural/remote communities and minority ethnic groups who are underrepresented in health professions. Canada's Northern Ontario School of Medicine is one example of situating training within rural and remote communities, which has a positive impact on trainees and the community. ${ }^{47,48}$ High school programs can train certified nursing assistants, certified medical office assistants, and dental hygienists. Partnering with local community colleges and expanding existing programs will make these entry-level professions accessible to more individuals. In addition, special care is needed to ensure that those employees who desire to move beyond entry-level jobs have the support to do so.
Finally, care of populations made vulnerable by racist social and economic policies should be embedded in medical school education and training to increase trainees' interest in practicing in areas where they are most needed. ${ }^{49}$

\section{Recommendation 4: Design Information Technology That Serves the Patient, Family, and the Interprofessional Care Team}

The COVID-19 pandemic has forced many primary care clinicians to pivot rapidly to virtual care to serve patients and families. While virtual care has minimized virus transmission risk, it was not without challenges regarding privacy, ownership, longitudinal care, chronic disease management, and health care access. In some ways, virtual care has improved health equity and access to care (ie, improved rural access to telepsychiatry and teledermatology services even before the pandemic). ${ }^{50-52}$ The rapid pivot, however, adversely affected many who were already marginalized, because those who are both poor and minoritized are much less likely to have the devices or technical knowledge to make the video visits work. ${ }^{53,54}$

A person- and community-centered, data-driven approach is needed to customize primary care services and enable interprofessional teams to meet the needs of the population they serve. Careful EMR collection of accurate, self-identified race/ethnicity data, sexual orientation, gender identity, and disability is an important first step to providing whole-person equitable care. ${ }^{55}$ Concerns over commercial secondary use of virtual care data have been raised. Health systems need to develop and adopt clear virtual care guidelines and policies that uphold patient privacy, health equity, and quality care. Historically disadvantaged communities need to be included in the governance discussions and decisions around the use of their own health data, given inherent systemic racism and decades of data and research misuse and exploitation endured by Indigenous and Black communities. ${ }^{56-58}$

Software developers, researchers, and analysts must ensure that developed algorithms are free of bias and enhance patient care. For example, recent evidence suggest that some EMR-based decision support tools have increased bias because they were based on inaccurate race data and limited training sets. ${ }^{59,60}$ Algorithms designed for public health should be accessible (open source, nonpropriety) so that they can be externally validated and audited to ensure their equitable performance in each locale for which they are employed. ${ }^{61}$

Thus, information technology and artificial intelligence tools should take a health equity-informed approach as they collect and incorporate race, ethnicity, and other sociodemographic data into their coding and analysis algorithms.

\section{Recommendation 5: Ensure High-Quality Primary Care is Implemented}

Implementing high-quality care will require innovative approaches that are health equity-focused. ${ }^{62}$ One approach is social prescribing, which integrates support for finances, food, shelter, and social needs into primary care. ${ }^{63}$ Social 
prescribing takes many forms depending on the community served, resources available, and patient needs. It may include prescribing financial support, food access, trauma-informed counseling, a knitting circle, or a walking group. Social prescribing can improve mental health, social integration, physical activity, and disease self-management. Social prescribing acknowledges social determinants of health and is based on meaningful engagement of patient "health champions" (patients who promote healthy lifestyles by inspiring others to take a more active role in their health), primary care clinicians, and allied health professionals in a team-based model of care focusing on health equity. ${ }^{64}$

Direct evidence on the importance of having an equityfocused approach to primary care quality improvement is also reflected in a recent comparative study of adult mortality rates in Ontario and England. ${ }^{65}$ The study showed a significant improvement of $10 \%$ in the relative gap in mortality by income in England compared to Ontario, because England had prioritized an explicit primary care policy targeting health inequity reduction. In contrast, Ontario focused on improving overall access (in addition to increasing screening and other specific services) for the entire population. ${ }^{65}$

\section{DISCUSSION}

The importance of health equity, diversion, and inclusion (EDI) has been realized, thanks to a heightened awareness of health outcomes and vaccination inequities during the syndemics of COVID-19 and racialized police violence. ${ }^{66,67}$ The changes in the global narrative brought about by these syndemics have created a shift from "race-based" to "racism-based" or "race-conscious" medicine. ${ }^{56}$ A new level of accountability for health systems, academic medical centers, medical societies, health care organizations, and stakeholders is emerging. Thus, having well defined and detailed EDI accountability metrics will be central to ensuring implementation of high-quality primary care. The foundational components of those metrics include a common lexicon for EDI initiatives focusing on the diversity of primary care clinicians, leaders, and team members and a core emphasis on meaningful patient engagement and community partnerships. Organizations need to review and make honest appraisals of strategic plans, mission statements, and statements of values, as these statements may not promote EDI. ${ }^{68}$ A critical component of EDI accountability metrics includes evaluation criteria for senior leaders that are linked to compensation. Senior leadership accountability must be based on the benefits that EDI brings to the organization and not merely on the numbers of people for diversity's sake.

Information technology, interprofessional health care, community partnerships, patient-engagement teams, and data need to reflect the rich diversity of our planet. EDI training and familiarity with the EDI literature will position health care organizations for success in implementing high-quality primary care. Moreover, awareness of primary care quality measures is important. As defined by the Healthcare Effectiveness Data and Information Set (HEDIS), current quality measures are used by most health systems in the United States. They are followed closely by leadership to measure health care quality of care performance, and some clinician bonuses are contingent upon meeting the HEDIS quality goals. Overall, funding and staffing allocations need to be informed by an equity-focused policy that is transparent and involves all stakeholders' input. This will require relationship building and ongoing intersectoral teamwork to meet current and future health care needs.

Ultimately, primary care availability is largely dependent on political and policy decisions that may or may not address the needs of all patients and communities. ${ }^{69,70}$ Decision-making bodies need to have an equitable representation to ensure a health equity focus of primary care expansion, where services are not limited to areas with the greatest possibility for profit, but rather to where unmet health needs are the greatest. ${ }^{71}$ Without a policy focus on health equity, primary care reform may worsen the already existing health inequities.

\section{CONCLUSION}

Implementing NASEM recommendations to achieve highquality primary care is going to take deliberate, sustainable efforts from health care systems, policy makers, primary care networks, medical societies, medical schools, and health care organizations. Ongoing work by the national academies and other stakeholders with an EDI and healthy equity focus is needed to reinvigorate primary care. As we move toward the next stages of primary care reform, having a health equityinformed public policy will be key to reduce and eliminate existing health inequities and ensure provision of high-quality primary care.

Read or post commentaries in response to this article.

Key words: health equity; health system reform; primary care reform; racism in medicine; exclusion in medicine; coronavirus pandemic

Submitted August 14, 2021; submitted, revised, November 13, 2021; accepted December 1, 2021.

\section{References}

1. Blumenthal D, Fowler EJ, Abrams M, Collins SR. Covid-19 - implications for the health care system. N Engl J Med. 2020;383(15):1483-1488. 10.1056/ NEJMsb2021088

2. van Weel C, Kidd MR. Why strengthening primary health care is essential to achieving universal health coverage. CMAJ. 2018;190(15):E463-E466. 10.1503/cmaj.170784

3. O'Neill B, Ferrer R, O'Brien $P$, et al. Improving equity through primary care: proceedings of the 2019 Toronto international conference on quality in primary care. Ann Fam Med. 2020;18(4):364-369. 10.1370/afm.2560

4. Mercer SW, Patterson J, Robson JP, Smith SM, Walton E, Watt G. The inverse care law and the potential of primary care in deprived areas. Lancet. 2021; 397(10276):775-776. 10.1016/S0140-6736(21)00317-2

5. Teutsch S, Carey TS, Pignone M. Health equity in preventive services: the role of primary care. Am Fam Physician. 2020;102(5):264-265. https://www. aafp.org/afp/2020/0901/p264.html 
6. The Lancet. Taking urgent action on health inequities. Lancet. 2020;395 (10225):659. 10.1016/S0140-6736(20)30455-4

7. National Academies of Sciences Engineering and Medicine, Health and Medicine Division, Board on Health Care Services, Committee on Implementing High Quality Primary Care. Implementing High-Quality Primary Care: Rebuilding the Foundation of Health Care. National Academies Press; 2021 https://www.nap.edu/catalog/25983/implementing-high-quality-primarycare-rebuilding-the-foundation-of-health

8. Schneider EC, Shah A, Doty MM, Tikkanen R, Fields K, Williams RD. Mirror, Mirror 2021: Reflecting Poorly Health Care in the U.S. Compared to Other HighIncome Countries. The Commonwealth Fund; 2021. https://www.common wealthfund.org/publications/fund-reports/2021/aug/mirror-mirror-2021reflecting-poorly

9. Mueller M, Morgan D. Deriving Preliminary Estimates of Primary Care Spending Under the SHA 2011 Framework. OECD; 2019. https://www.oecd.org/health/ health-systems/Preliminary-Estimates-of-Primary-Care-Spending-underSHA-2011-Framework.pdf

10. Kringos DS, Boerma WGW, Hutchinson A, Saltman RB. Building Primary Care in a Changing Europe. The European Observatory on Health Systems and Policies; 2015. https://www.euro.who.int/_data/assets/pdf_file/0018/271170/ BuildingPrimaryCareChangingEurope.pdf

11. Foster KE, Johnson CN, Carvajal DN, et al. Dear white people. Ann Fam Med. 2021;19(1):66-69. 10.1370/afm.2634

12. Addressing Gender Equity and Diversity in Canada's Medical Profession: A Review. Canadian Medical Association; 2019. https://www.cma.ca/sites/ default/files/pdf/Ethics/report-2018-equity-diversity-medicine-e.pdf

13. Vélez MP, Slater M, Griffiths $R$, et al. Diabetes during pregnancy and perinatal outcomes among First Nations women in Ontario, 2002/03-2014/15: a population-based cohort study. CMAJ Open. 2020;8(1):E214-E225. 10.9778/ cmajo.20190195

14. Shah BR, Slater M, Frymire E, et al. Use of the health care system by Ontario First Nations people with diabetes: a population-based study. CMAJ Open. 2020;8(2):E313-E318. 10.9778/cmajo.20200043

15. Smedley BD, Stith AY, Nelson AR. Unequal Treatment: Confronting Racial and Ethnic Disparities in Health Care. National Academies Press; 2002.

16. Bushnik T, Tjepkema M, Martel L. Socioeconomic disparities in life and health expectancy among the household population in Canada. Health Rep. 2020;31(1):3-14. 10.25318/82-003-x202000100001-eng

17. Phillips RL, McCauley LA, Koller CF. Implementing high-quality primary care: a report from the National Academies of Sciences, Engineering, and Medicine. JAMA. 2021;325(24):2437-2438. 10.1001/jama.2021.7430

18. Wasson JH, Sox HC, Miller HD. Aligning payments, services, and quality in primary care. JAMA. 2021;326(9):805-806. 10.1001/jama.2021.12775

19. Institute of Medicine. Primary Care: America's Health in a New Era. National Academies Press; 1996.

20. Boyer Y. Healing racism in Canadian health care. CMAJ. 2017;189(46): E1408-E1409. 10.1503/cmaj.171234

21. DATA USA. Medical assistants. Deloitte US. Accessed Jul 29, 2021. https:// datausa.io/profile/soc/medical-assistants

22. DATA USA. Miscellaneous community \& social service specialists, including health educators $\&$ community health workers. Deloitte US. Accessed Jul 29 2021. https://datausa.io/profile/soc/miscellaneous-community-social-servicespecialists-including-health-educators-community-health-workers

23. Rosseter R. Enhancing diversity in the workforce. American Association of Colleges of Nursing. Updated Apr 1, 2019. Accessed Jul 29, 2021. https:// www.aacnnursing.org/news-information/fact-sheets/enhancing-diversity

24. Ryujin D, Spackman J, Honda TJ, et al. Increasing racial and ethnic diversity at the university of utah physician assistant program. Fam Med. 2021;53(5): 372-375. 10.22454/FamMed.2021.923340

25. Greenwood BN, Hardeman RR, Huang L, Sojourner A. Physician-patient racial concordance and disparities in birthing mortality for newborns. Proc Natl Acad Sci USA. 2020;117(35):21194-21200. 10.1073/pnas.1913405117

26. Traylor AH, Schmittdiel JA, Uratsu CS, Mangione CM, Subramanian U. The predictors of patient-physician race and ethnic concordance: a medical facility fixed-effects approach. Health Serv Res. 2010;45(3):792-805. 10.1111/ j.1475-6773.2010.01086.x
27. Rodriguez JE, Campbell KM, Adelson WJ. Poor representation of Blacks, Latinos, and Native Americans in medicine. Fam Med. 2015;47(4):259-263. https://www.stfm.org/familymedicine/vol47issue4/Rodriguez259

28. Lala R, Baker SR, Muirhead VE. A critical analysis of underrepresentation of racialised minorities in the UK dental workforce. Community Dent Health. 2021;38(2):142-149. 10.1922/CDH_IADRLala08

29. Mertz E, Calvo J, Wides C, Gates P. The Black dentist workforce in the United States. J Public Health Dent. 2017;77(2):136-147. 10.1111/jphd.12187

30. Wong S, Wong J. Representation of racial minority students in selected Canadian university schools of nursing. J Adv Nurs. 1980;5(1):83-90. 10.1111/ j.1365-2648.1980.tb00212.x

31. Sklar DP. Diversity, fairness, and excellence: three pillars of holistic admissions. Acad Med. 2019;94(4):453-455. 10.1097/ACM.0000000000002588

32. Rodríguez JE, Wusu MH, Anim T, Allen KC, Washington JC. Abolish the minority woman tax! J Womens Health (Larchmt). 2020;30(7). 10.1089/jwh. 2020.8884

33. Rodríguez JE, Campbell KM, Pololi LH. Addressing disparities in academic medicine: what of the minority tax? BMC Med Educ. 2015;15(1):6. 10.1186/ s12909-015-0290-9

34. Campbell KM, Rodríguez JE. Addressing the minority tax: perspectives from two diversity leaders on building minority faculty success in academic medicine. Acad Med. 2019;94(12):1854-1857. 10.1097/ACM.0000000000002839

35. Williamson T, Goodwin CR, Ubel PA. Minority tax reform - avoiding overtaxing minorities when we need them most. N Engl J Med. 2021;384(20):18771879. 10.1056/NEJMp2100179

36. Culhane-Pera KA, Pergament SL, Kasouaher MY, et al. Diverse community leaders' perspectives about quality primary healthcare and healthcare measurement: qualitative community-based participatory research. Int J Equity Health. 2021;20(1):226. 10.1186/s12939-021-01558-4

37. Bayoumi I, Schultz SE, Glazier RH. Primary care reform and funding equity for mental health disorders in Ontario: a retrospective observational population-based study. CMAJ Open. 2020;8(2):E455-E461. 10.9778/cmajo.20190153

38. Radinmanesh M, Ebadifard Azar F, Aghaei Hashjin A, Najafi B, Majdzadeh R. A review of appropriate indicators for need-based financial resource allocation in health systems. BMC Health Serv Res. 2021;21(1):674. 10.1186/ s12913-021-06522-0

39. Hong M, Thind A, Zaric GS, Sarma S. Emergency department use following incentives to provide after-hours primary care: a retrospective cohort study. CMAJ. 2021;193(3):E85-E93. 10.1503/cmaj.200277

40. Ontario HQ; Health Quality Ontario. Interventions to improve access to primary care for people who are homeless: a systematic review. Ont Health Technol Assess Ser. 2016;16(9):1-50. https://www.ncbi.nlm.nih.gov/pmc/ articles/PMC4832090/

41. Kouyoumdjian FG, Lamarche L, McCormack D, et al. 90-90-90 for everyone?: access to HIV care and treatment for people with HIV who experience imprisonment in Ontario, Canada. AIDS Care. 2020;32(9):1168-1176. 10.1080/09540121.2019.1679710

42. Kouyoumdjian F, Kim M, Kiran T, et al. Attachment to primary care and team-based primary care: retrospective cohort study of people who experienced imprisonment in Ontario. Can Fam Physician. 2019;65(10):e433-e442. https://www.cfp.ca/content/65/10/e433.long

43. College of Family Physicians of Canada, Canadian Psychiatric Association, and Canadian Psychological Association. Integrating Mental Health Services in Primary Care. College of Family Physicians of Canada, Canadian Psychiatric Association, and Canadian Psychological Association; 2020.

44. Hing E, Hsiao CJ. State variability in supply of office-based primary care providers: United States, 2012. NCHS Data Brief. 2014;(151):1-8. https://www. cdc.gov/nchs/products/databriefs/db151.htm

45. O'Connor A, Wellenius G. Rural-urban disparities in the prevalence of diabetes and coronary heart disease. Public Health. 2012;126(10):813-820. 10.1016/j.puhe.2012.05.029

46. Doescher MP, Keppel GA, Skillman SM, Rosenblatt RA. Rural Health Research Center Policy Brief: the crisis in rural dentistry. Published Apr 2009. https:// depts.washington.edu/uwrhrc/uploads/Rural_Dentists_PB_2009.pdf

47. Strasser R, Hogenbirk JC, Minore B, et al. Transforming health professional education through social accountability: Canada's Northern Ontario School of Medicine. Med Teach. 2013;35(6):490-496. 10.3109/0142159X.2013.774334 
48. Hogenbirk JC, Robinson DR, Strasser RP. Distributed education enables distributed economic impact: the economic contribution of the Northern Ontario School of Medicine to communities in Canada. Health Econ Rev. 2021;11(1):20. 10.1186/s13561-021-00317-z

49. Sharma M, Pinto AD, Kumagai AK. Teaching the social determinants of health: a path to equity or a road to nowhere? Acad Med. 2018;93(1):25-30. 10.1097/ACM.0000000000001689

50. Elsner P. Teledermatology in the times of COVID-19 - a systematic review. J Dtsch Dermatol Ges. 2020;18(8):841-845. 10.1111/ddg.14180

51. Kennedy J, Arey S, Hopkins Z, et al. Dermatologist perceptions of teledermatology implementation and future use after COVID-19: demographics, barriers, and insights. JAMA Dermatol. 2021;157(5):595-597. 10.1001/ jamadermatol.2021.0195

52. O'Brien M, McNicholas F. The use of telepsychiatry during COVID-19 and beyond. Ir J Psychol Med. 12 2020;37(4):250-255. 10.1017/ipm.2020.54

53. Ramsetty A, Adams C. Impact of the digital divide in the age of COVID-19. J Am Med Inform Assoc. 0701 2020;27(7):1147-1148. 10.1093/jamia/ocaa078

54. Ortega G, Rodriguez JA, Maurer LR, et al. Telemedicine, COVID-19, and disparities: policy implications. Health Policy Technol. 2020;9(3):368-371 10.1016/j.hlpt.2020.08.001

55. Baker KE, Streed CG Jr, Durso LE. Ensuring that LGBTQI+ people count collecting data on sexual orientation, gender identity, and intersex status. N Engl J Med. 2021;384(13):1184-1186. 10.1056/NEJMp2032447

56. Cerdeña JP, Plaisime MV, Tsai J. From race-based to race-conscious medicine: how anti-racist uprisings call us to act. Lancet. 2020;396(10257):1125-1128. 10.1016/S0140-6736(20)32076-6

57. Bajaj SS, Stanford FC. Beyond Tuskegee - vaccine distrust and everyday racism. N Engl J Med. 2021;384(5):e12. 10.1056/NEJMpv2035827

58. Burgess RA, Osborne RH, Yongabi KA, et al. The COVID-19 vaccines rush: participatory community engagement matters more than ever. Lancet. 2021; 397(10268):8-10. 10.1016/S0140-6736(20)32642-8

59. Obermeyer Z, Powers B, Vogeli C, Mullainathan S. Dissecting racial bias in an algorithm used to manage the health of populations. Science. 2019; 366(6464):447-453. 10.1126/science.aax2342
60. Buolamwini J, Gebru T. Gender Shades: Intersectional accuracy disparities in commercial gender classification. Proc Mach Learn Res. 2018;81:77-91. http:// proceedings.mlr.press/v81/buolamwini18a.html

61. Van Calster B, Wynants L, Timmerman D, Steyerberg EW, Collins GS. Predictive analytics in health care: how can we know it works? J Am Med Inform Assoc. 2019;26(12):1651-1654. 10.1093/jamia/ocz130

62. Pinto AD, Bloch G. Framework for building primary care capacity to address the social determinants of health. Can Fam Physician. 2017;63(11):e476-e482.

63. Mulligan K, Bhatti S, Rayner J, Hsiung S. Social prescribing: creating pathways towards better health and wellness. J Am Geriatr Soc. 2020;68(2):426428. 10.1111/jgs.16249

64. Bhatti S, Rayner J, Pinto AD, Mulligan K, Cole DC. Using self-determination theory to understand the social prescribing process: a qualitative study. BJGP Open. 2021;5(2):BJGPO.2020.0153. 10.3399/BJGPO.2020.0153

65. Cookson R, Mondor L, Asaria M, Kringos DS, Klazinga NS, Wodchis WP. Primary care and health inequality: difference-in-difference study comparing England and Ontario. PLoS One. 2017;12(11):e0188560. 10.1371/journal. pone.0188560

66. Eissa A, Lofters A, Akor N, Prescod C, Nnorom O. Increasing SARS-CoV-2 vaccination rates among Black people in Canada. CMAJ. 2021;193(31):E1220E1221. 10.1503/cmaj.210949

67. Bailey ZD, Feldman JM, Bassett MT. How structural racism works - racist policies as a root cause of US racial health inequities. N Engl J Med. 2021; 384(8):768-773. 10.1056/NEJMms2025396

68. Campbell KM, Tumin D. Mission matters: association between a medical school's mission and minority student representation. PLoS One. 2021;16(2): e0247154. 10.1371/journal.pone.0247154

69. Lawson E. The political determinants of health. Br J Gen Pract. 2020;70(701): 571. $10.3399 /$ bjgp20X713525

70. Dawes DE, Williams DR. The Political Determinants of Health. Johns Hopkins University Press; 2020.

71. Martin D, Miller AP, Quesnel-Vallée A, Caron NR, Vissandjée B, Marchildon GP. Canada's universal health-care system: achieving its potential. Lancet. 2018;391(10131):1718-1735. 10.1016/S0140-6736(18)30181-8 